\title{
A autoavaliação de escolas: tensões e sentidos da ação
}

\author{
Ana Paula Correia*, Isabel Fialho*, Virgínio Sá** \\ *Universidade de Évora, **Universidade do Minho/IE
}

\begin{abstract}
Resumen
Integrada numa investigação mais ampla, com a finalidade de averiguar os efeitos do programa de avaliação externa das escolas (AEE) nas dinâmicas de autoavaliação e nos planos de melhoria da escola, nesta comunicação restringe-se a abordagem e procura-se conhecer como se desenvolve o processo de autoavaliação nas escolas. Os resultados preliminares evidenciam que, nas respostas às prescrições externas para a avaliação e melhoria, as escolas recorrem a estratégias e táticas plurais, daí que as formas assumidas pela autoavaliação, mais do que alimentarem processos de melhoria configuram processos de adaptação que lhes permitem assegurar a credibilidade social e a legitimidade organizacional.
\end{abstract}

Palabras clave: autoavaliação da escola, respostas estratégicas, melhoria educativa, credibilidade social.

No contexto educativo português a questão da avaliação das organizações escolares tem vindo a ocupar um lugar de destaque na agenda das políticas educativas, onde os processos de avaliação externa e de autoavaliação são apontados como instrumentos decisivos para a melhoria da qualidade do serviço educativo. Porém, numa era de responsabilização (accountability) das escolas pelos resultados escolares, de aumento da pressão para avaliações externas e de elaboração de rankings, não tem sido fácil para as escolas desenvolverem processos de autoavaliação que consigam promover a capacidade interna de mudança (Bolívar, 2012) e de melhoria. Perante as pressões e exigências, por vezes contraditórias, quer de uma "ordem institucional de mercado", quer de um "Estado institucional", as organizações escolares vivem hoje, na questão da autoavaliação de escola, numa encruzilhada de tensões entre proporcionar, por um lado, indicadores que permitam aferir a qualidade da escola na sua "versão mercantil" e, por outro, criar formas de autoavaliação congruentes com o seu ethos escolar e com a melhoria da escola na sua totalidade. A este cenário acresce $\mathrm{o}$ facto das políticas nem sempre proporcionarem os estímulos e as condições adequados à aprendizagem e capacitação dos atores para o desenvolvimento de práticas de autoavaliação e de ações de melhoria (Afonso, 2010; Alves \& Correia, 2008). Neste contexto, é nosso objetivo contribuir para o conhecimento de como se desenvolve o processo de conceção e implementação da autoavaliação nas escolas.

\section{Método}

Esta comunicação enquadra-se numa investigação mais ampla, em curso, que se propôs averiguar de que modo o programa de Avaliação Externa das Escolas (AEE), contribui para o desenvolvimento nas escolas de dinâmicas e práticas de autoavaliação que sustentem a elaboração de planos de ação que possibilitem a melhoria da escola. Inserida numa matriz de cariz essencialmente qualitativa, a investigação na qual a comunicação se baseia opta pelo estudo de caso aplicado a "cinco casos", pois partimos do pressuposto da existência de tipos diferentes de condições entre os casos a nível do contexto organizacional e das dinâmicas inerentes aos processos avaliativos (Yin, 2005). Nesta comunicação questiona-se: como se desenvolve o processo de conceção e implementação da autoavaliação .

Os dados empíricos aqui mobilizados foram recolhidos através da realização de entrevistas semiestruturadas, em cada um dos casos em estudo (três agrupamentos de escola - AG1, AG2 e AG3 - e duas escolas secundárias - ES1, ES2). Em cada agrupamento/escola não agrupada entrevistámos o diretor (E1); o coordenador da equipa de autoavaliação (E2); o presidente do conselho geral (E3); um coordenador de departamento (E4); um professor do conselho geral (E5); um encarregado de educação (EE); um aluno (AL) e um elemento do pessoal não docente (ND). Procurámos sobretudo obter informação e conhecimento através dos protagonistas do processo avaliativo. Os dados recolhidos através das entrevistas foram tratados através da análise de conteúdo (Bardin, 2009). Para concretizar a análise de conteúdo produziuse um sistema de categorias de modo a que os dados, para cada uma das dimensões, pudessem ser agregados em unidades de sentido, em função das categorias definidas.

\section{Resultados e discussão}

Para efeitos desta análise selecionamos apenas os excertos das entrevistas em que confrontámos os inquiridos sobre o modo como se desenvolve o processo de conceção e implementação da autoavaliação de escola. Neste contexto apresentamos apenas os dados relativos a essa dimensão.

\section{O processo de autoavaliação de escola nas escolas}

Da análise de conteúdo aos discursos dos entrevistados pareceu-nos pertinente a apresentação dos resultados ao nível das categorias mais relevantes, como sejam: i) A decisão sobre a autoavaliação; ii) A equipa de autoavaliação; iii) Os domínios e campos de análise da autoavaliação; iv) $O$ envolvimento dos atores no processo de autoavaliação; v) Uso e fins dos resultados da autoavaliação.

Este trabalho é financiado por Fundos FEDER através do Programa Operacional Fatores de Competitividade - COMPETE e por Fundos Nacionais através da Fundação para a Ciência e Tecnologia (FCT) no âmbito do projeto Impacto e Efeitos da Avaliação Externa nas Escolas do Ensino não Superior (PTDC/CPECED/116674/2010).

Correspondencia: Ana Paula Correia, apcorreia.svp@gmail.com

Selección y peer-review bajo responsabilidad del Grupo de Investigación G000422-GIPDAE, Universidade da Coruña, España. 
A decisão sobre a autoavaliação. Ao procurarmos perceber as perceções dos atores educativos entrevistados acerca do modo como se desenvolveu o processo de decisão sobre a autoavaliação de escola (AA) constata-se que ao nível da subcategoria "Iniciativa da decisão", em todas as escolas a decisão de implementação do processo de AA, esteve centralizada num ator em particular- o diretor -, não resultando de uma preocupação compartilhada pelos atores da escola e do compromisso comum em avançar com o processo, no sentido de melhorar a qualidade da prestação do serviço educativo. $\mathrm{O}$ certo é que, sem o compromisso dos atores (Bolívar, 2012) pela melhoria, os esforços de mudança ficam com os seus efeitos bastante limitados.

Entre as razões convocadas pelas escolas para a implementação da AA, é possível identificar, ao nível da subcategoria "Motivos da decisão", motivos comuns a todas as escolas (exceto a AG2) como a "proximidade da AEE" (AG1-E2), a "preparação para a AEE" (ES2E2), a "obrigatoriedade legal" (AG3-E2) e a "necessidade de responder aos pontos fracos apontados pela AEE" (ES1-E2). O que sugere que o incentivo para a decisão passou pela conformidade legal e pela resposta à pressão institucional da $\mathrm{AEE}, \operatorname{logo}$ o processo de AA emerge como uma avaliação interna com caráter impositivo, na medida em que as escolas foram "obrigadas a escolher livremente" (Sá, 2009) implementar o seu processo, o que poderá vir a colocar em causa o objetivo de melhoria que se pretende. $\mathrm{Na}$ escola AG2, os motivos mais relevantes da tomada de decisão tiveram a ver, quer com a "necessidade de monitorização da execução das metas definidas no Projeto Educativo (PEE) em termos de resultados escolares" (E2), quer com a possibilidade de proceder a "alterações e sugestões de mudança ao projeto de intervenção do diretor" (E1). Parece assim sobressair uma preocupação centrada numa agenda gerencialista e tecnocrática, como resposta ao novo paradigma da "gestão escolar" (Torres, 2013), o que face à "obsessão" pela performatividade poderá remeter para uma lógica de avaliação para o mercado (Costa \& Ventura, 2005).

A equipa de autoavaliação. Quanto à constituição da equipa de AA, apenas nas escolas ES1 e ES2 é composta por atores educativos que representam os diferentes grupos da comunidade (docentes, pessoal não docente, encarregados de educação, alunos e/ou outros elementos da comunidade) integrando, ainda, na escola ES1 um "amigo crítico". Na escola AG1 a perspetiva dos alunos não é tida em conta; na escola AG2 apenas os docentes e encarregados de educação constituem a equipa; e na escola AG3 a equipa é constituída apenas por docentes. A análise permite inferir que estas escolas não contemplam no desenvolvimento do processo de AA as visões e interpretações dos diferentes stakeholders, correndo assim o risco de não atender à complexidade da organização escolar (Alaíz, Góis \& Gonçalves, 2003).

Em todas as escolas (à exceção da AG1), fazem parte da equipa elementos da direção (diretor, ou um dos adjuntos, ou assessor), sendo mesmo nas escolas AG2 e
AG3 coordenadas por esses elementos. Em consequência, face ao poder hierárquico da direção, emerge a perceção da AA como um instrumento de controlo burocrático e de sancionamento. $\mathrm{Na}$ medida em que a avaliação da escola envolve questões políticas, a integração de elementos da direção na equipa de AA poderá indiciar uma estratégia de controlo do processo por parte das direções, sendo que o domínio das "zonas de incerteza" thes vai assegurar, dentro da incerteza, a possibilidade de controlar o "jogo de poder" (Crozier \& Friedberg, 1977).

Quanto à subcategoria "Critérios de constituição da equipa" os indicadores mais expressivos mostram critérios comuns utilizados pelas direções, em todas as escolas (exceto na escola AG1), na escolha do coordenador da equipa de AA como a "formação especializada" (AG2-E1), as "competências técnicas" (ES2-E4) e as "experiências anteriores e desempenho técnico" (ES1-E1). Na escola AG1 o critério utilizado, pela diretora, na escolha do coordenador assentou no critério administrativo de existência de "disponibilidade temporal no seu horário", uma vez que o docente "tinha muitas horas de redução" (AG1-E1). Quanto aos critérios de escolha dos outros docentes passaram pela "confiança" (caso da escola AG1), pela "representatividade das diversas estruturas" (caso da AG3 e da ES1), pela "experiência adquirida em avaliações anteriores" (caso da ES1) e pela "redução de horário" (caso da ES2). Quanto aos restantes elementos, nas situações em que estes integram a equipa, a sua escolha resultou, no caso dos alunos e encarregados de educação do facto de pertencerem à associação de estudantes e de pais, no caso dos não docentes da "disponibilidade" e "experiência na escola".

A escola AG2 optou por uma "lógica institucional" na constituição da equipa, pois os seus elementos integram "uma das seções do conselho pedagógico da escola" (E1). Se atentarmos que, nesta escola, a AA segue a forma de uma avaliação segundo padrões (Bolívar, 2012), esta "opção" de constituição da equipa sugere que o diretor, numa lógica gerencialista, procura, por um lado, legitimar a ação da equipa através do poder estrutural inerente ao órgão e, por outro, garantir a "coesão organizacional" em torno da questão de responsabilização dos atores pelos resultados escolares alcançados.

$\mathrm{Na}$ subcategoria "Modos de funcionamento da equipa" pudemos verificar que as dinâmicas diferem nas diversas escolas. Quanto à realização de reuniões da equipa observámos que apenas nas escolas ES1 e AG2 os elementos docentes das equipas têm como rotina reunir semanalmente. Nas escolas AG1 e AG3, no decurso do ano letivo, as equipas não realizaram reuniões com a totalidade dos seus elementos devido à "falta de horário para trabalho conjunto" (AG1-E1) e à "falta de motivação dada a expetativa de agregação da escola" (AG3-E2). Na escola ES2 foram realizadas na totalidade, durante o ano letivo, três reuniões "da equipa ampliada"(E2). Nesta escola a "nova" equipa reiniciou os seus trabalhos no presente ano letivo (2011/2012), "devido à proximidade da $\operatorname{AEE~}\left(2^{\circ}\right.$ ciclo)" sendo a sua composição "idêntica à própria composição do conselho 
geral" (E1). Esta escola fez refletir na "comissão de avaliação interna o próprio conselho geral" (E1) existindo ainda "a comissão restrita da avaliação" composta pela diretora e pelo coordenador.

Quanto à conceção dos dispositivos de AA e implementação do processo, em todas as escolas (exceto a ES1) a tomada de decisão e execução dos trabalhos da são realizados, quase exclusivamente, pelo coordenador da equipa, pois é o único elemento que, para além de dispor de "formação específica" (AG2-E2), tem espaço temporal no seu "horário para os trabalhos da AA"(AG3-E2). Percebe-se assim que o modo de funcionamento das equipas é reduzido a um nível de dinamização unipessoal. Logo, as tarefas de AA não resultam do confronto de perspetivas e da partilha ativa dos diversos elementos, os quais deveriam decidir em conjunto o processo de construção e de implementação da AA, bem como, interpretar os seus resultados (Alaiz, et al., 2003). Em todas as escolas, o "motor" da conceção e implementação do processo são sobretudo os docentes (Correia, 2011). Embora a dinâmica necessária aos trabalhos da equipa não se coadune com a disponibilidade de horários dos outros elementos da equipa, o certo é que a participação não equitativa e equilibrada poderá gerar sentimentos de desmotivação e desinteresse que pouco contribuem para a obtenção de diferentes perspetivas sobre a escola.

$\mathrm{Na}$ escola ES1 "a tomada de decisão e execução dos trabalhos de autoavaliação resulta da partilha e trabalho conjunto entre os elementos docentes da equipa" (E1), os quais dispõem, para isso, de espaço temporal comum no seu horário semanal, embora o trabalho técnico seja realizado pelo consultor externo, que designam de "amigo crítico" (E2), o qual procede ao tratamento dos dados dos inquéritos, proporcionando ainda formação.

Os domínios e campos de análise da autoavaliação. Quanto ao "modelo e dispositivos de AA" pudemos verificar que as opções diferem nas diversas escolas. A escola AG1 que não utiliza nenhum modelo formal procedeu à aplicação de questionários de modo a obter a opinião dos pais acerca de aspetos do funcionamento dos espaços escolares, e dos alunos sobre alguns aspetos do processo de escolarização. As escolas AG3 e ES2 procederam à adaptação de modelos formais existentes na literatura especializada e, em paralelo, à monitorização dos resultados escolares. A escola AG2 tem um modelo próprio, ou seja, procede à monitorização dos resultados escolares, tendo como referente as metas definidas no PEE. Trata-se, neste caso, de uma avaliação quantitativa, comparativa, em que se procura através da referencialização (Figari, 2008) e da interpretação dos resultados obtidos verificar o cumprimento das performances definidas previamente, pois "o diretor tem o seu projeto de intervenção que é necessário acompanhar” (AG2-E2), e proceder à "responsabilização dos atores por esses resultados" (AG2-E5). Face à análise, pode afirmar-se que o processo de AA ao assentar na monitorização do PEE, através da quantificação, mensuração e comparação dos resultados obtidos às metas definidas, rege-se por pressupostos racionais e gerencialistas, próprios de uma visão da escola como empresa educativa (Costa, 1998). A escola ES1 utiliza o modelo Common Assessment Framework (CAF), com apoio de consultor externo e procede em paralelo à conceção de um modelo para avaliação de quatro dimensões da sala de aula: "avaliação das aprendizagens"; "relação pedagógica"; "estratégias de ensino"; "recursos e instrumentos". Este último modelo, ainda em fase de construção, procura sobretudo "a monitorização da eficácia das medidas de desempenho pedagógico emanadas da direção e do conselho pedagógico" (ES1E1). Trata-se de uma avaliação quantificada que, tendo em conta os "indicadores de desempenho pedagógico definidos antecipadamente pelos docentes" (ES1E2), mostra em termos de resultados um ranking de desempenhos pedagógicos de cada docente. Também nesta escola as respostas mais relevantes apontam para o facto da AA assegurar a manutenção da "imagem de referência da escola" (ES1-E2), o que configura estarmos perante uma AA ao serviço do mercado (Costa \& Ventura, 2005).

Todas as escolas procederam, à adaptação do quadro de referência dos seus modelos aos domínios do referencial da AEE (excetuando a escola AG1), pois assim vão conseguir "dar uma resposta rápida ao que nos é pedido" (ES2-E2) ou, "dar alguma resposta e algum feedback àquela avaliação externa” (AG2-E2), ou ainda para "verificar a evolução em relação à avaliação anterior" (AG3-E1). A análise permite inferir, por um lado, que o isomorfismo mimético (DiMaggio \& Powell, 1999) emerge como estratégia de respostas às pressões do meio institucional e, por outro, que as escolas tendem a incorporar os arranjos estruturais e os procedimentos levados a cabo por outras organizações que reconhecem como credíveis e legitimadas.

O envolvimento dos atores no processo. Quanto às formas de participação dos atores educativos no processo de AA constata-se que o modo como as escolas envolvem os atores também não é idêntico. $\mathrm{Na}$ escola AG1 verifica-se a "ausência de envolvimento" dos docentes, limitando-se a participação apenas aos pais e encarregados de educação e aos alunos na resposta aos questionários de opinião. Em consequência "os docentes ainda não entendem isso como uma necessidade, pois não lhes chega" (AG1-E4). O que permite inferir estarmos perante uma situação de heteroavaliação (Palma, 2001). Na escola AG3 o processo de AA "diz respeito muito mais a um grupo restrito da escola" (AG3-E3), ou seja "está demasiado centrado na equipa de AA, sabemos que o grupo reúne, mas fora isso nós não temos grande noção do que está a ser feito" (AG3-E3). O que significa que "o processo não tem um grande peso para a grande massa da escola" (AG3-E1). Percebe-se que a autoavaliação é processo pouco participado e sobretudo a cargo da direção e dos elementos da sua confiança, configurando também uma situação de heteroavaliação. Neste cenário dificilmente a AA será assumida pelos atores como um instrumento orientador para a melhoria das práticas, sendo antes um instrumento de ritualização ao serviço da legitimação. $\mathrm{Na}$ escola ES2, a participação dos atores foi bastante fluída, pois apenas se verificou a "participação pontual 
de alguns docentes" (ES2-E5). O processo de AA foi interrompido após a AEE, e com o reinício do processo o envolvimento dos atores limitou-se à participação dos elementos da equipa de AA, no "preenchimento do PAVE para tomar a decisão sobre qual a área que iriamos aprofundar" (ES2-E2). A falta de divulgação inicial dos objetivos da AA gerou um clima de desconfiança e alguma resistência dos docentes à participação ativa no processo. De tal modo que "naquela altura havia quem chamasse à equipa a ASAE" (ES2-E1), o que parece sugerir a perceção da AA como um instrumento ao serviço do controlo e da prestação de contas. Em consequência, na fase de divulgação dos resultados da AA, geraram-se situações de conflito, por um lado, entre os docentes e a equipa, "apenas foram observadas algumas aulas e quando as pessoas veem uma recomendação a dizer que os resultados poderiam ser não sei o quê (...), as pessoas sentiram-se" (ES2E1), e por outro, entre a equipa e a direção, "o conselho executivo não se reconhecia em algumas daquelas conclusões (...) havia aspetos em que se criticava (...) e com toda a certeza que estes aspetos não agradaram" (ES2-E2). Face à análise, parece-nos que o processo de AA decorreu num quadro de "jogos de poder" e "jogos de relação de poder" (Crozier \& Friedberg, 1977), tendo uma funcionalidade limitada na medida em que os atores o percecionaram como um instrumento de controlo político. As escolas AG2 e ES1 procederam ao envolvimento da generalidade dos docentes, quer na fase de divulgação inicial dos objetivos, quer na fase de divulgação de resultados da AA, o que conduziu a um maior compromisso no decurso do processo. Na escola ES1 todos os docentes participaram na identificação dos pontos fortes e fracos no âmbito da aplicação dos inquéritos da CAF, assim como, na "definição conjunta dos indicadores" (ES1-E2) necessários à construção do novo modelo de avaliação do desempenho das práticas pedagógicas. Embora os indicadores do novo modelo tenham resultado de uma co-construção pelos docentes, a divulgação dos seus resultados gerou um ambiente de competição entre os docentes: “embora vá poucas vezes à sala dos professores senti o mal estar que havia entre aqueles que por causa disso se sentiam os melhores e aqueles que se sentiram um bocadinho humilhados e isto cria divisões" (ES1-E5). O que permite inferir que a AA veio reforçar as micropolíticas existentes na escola e acentuar a balcanização (Hargreaves, 1998). Na escola AG2, foram promovidas reuniões, com a generalidade dos docentes, para análise dos resultados da AA, de modo a analisar os desvios dos resultados escolares face às metas do PEE e definir estratégias de remediação. No entanto a falta de assunção, por parte dos docentes, das metas do PEE como referente orientador da ação conduziu a uma postura de recusa de definição de estratégias, não só pela falta de identificação com os referentes, como por percecionarem a AA como uma forma de prestação de contas do seu desempenho e de responsabilização, nomeadamente, quando são "conduzidos" a debruçarem-se sobre o insucesso. Como tal, são "poucos os docentes que entendem a avaliação da escola como uma necessidade" (AG2-E2), assim colaboram no processo "porque acham que sim, mas é uma questão burocrática e administrativa, ainda não é visto com algo para melhorar" (AG2-E2). Poderá assim inferir-se que em todas as escolas o processo de AA não resulta do compromisso dos atores em perceber as práticas e os resultados alcançados e encontrar as estratégias mais adequadas para a melhoria, tendo como referente o seu PEE. Ao resultar da participação e do envolvimento de apenas alguns atores o processo de AA é concebido sobretudo como um processo burocrático de ritualização da eficácia da ação organizacional, sendo interiorizado pelos atores como "dado adquirido".

Usos e fins dos resultados da autoavaliação de escola. Quanto às perceções acerca dos usos e fins dos resultados da AA, embora em todas as escolas os relatórios de AA tenham sido divulgados nas estruturas formais, como o "conselho geral", o "conselho pedagógico" e "os departamentos", não encontramos evidências de terem sido promovidos processos de reflexão que possam comprometer os atores com a melhoria. Neste contexto, os principais utilizadores dos resultados da AA são as respetivas direções. Nas escolas AG1, AG2 e ES2 após os resultados do processo de AA não foram elaborados nem implementados planos de ação que possibilitem a melhoria. Na escola AG3, embora tivessem sido planificadas algumas ações de melhoria, "essas ações foram obtidas através de uma pressão exercida por parte da equipa" (AG3-E2), o que conduziu a que fosse difícil concretizar a sua implementação. Na escola ES1 foi elaborado e implementado um plano de ação de melhoria, gizado pelo consultor externo, na sequência dos procedimentos do próprio modelo de avaliação. Todavia, se considerarmos que as ações de melhoria têm como foco os pontos fracos apontados pela AEE e que a construção do plano de melhoria se inscreve numa lógica de "encomenda" (Leite, Rodrigues \& Fernandes, 2006), este plano poderá ter apenas a função de "ficar bem na fotografia" (Sá, 2009) e não a melhoria efetiva, tanto mais que os atores que intervêm diretamente nos processos educativos acabam por não participar como decisores da mudança e da melhoria. A divulgação, aos pais e encarregados de educação, dos resultados dos indicadores do modelo de desempenho pedagógico, com o ranking de desempenho de cada departamento curricular, permite concluir que a utilização da AA se enquadra numa estratégia de gestão/promoção da imagem pública da escola. Como refere um dos entrevistados "eles mostraram-se muito satisfeitos, não tanto pelos resultados, embora também orgulhosos de terem os filhos numa escola que tem resultados tão bons da parte dos alunos e professores" (ES1-E2). Na escola AG2 após os resultados da AA não foi elaborado um plano de melhoria, mas os docentes foram confrontados, numa lógica de responsabilização, com os "desvios" da avaliação obtida face às metas definidas e os resultados da AA tiveram implicações nas classificações obtidas na sua avaliação de desempenho. Esta situação levou à alteração de algumas práticas "as pessoas naturalmente já têm mais cuidado com o trabalho que fazem porque (...) depois as pessoas são responsabilizadas"(AG2-E4), 
consequentemente, "os professores mudaram as suas práticas têm mais cuidado e tentam que se atinjam os objetivos do projeto de intervenção do diretor" (AG2E5). Esta pressão reduziu as margens de autonomia instituinte do trabalho de cada docente, na medida em que este passou a ser fortemente influenciado pela ideia da ação eficaz de modo à obtenção de melhores resultados. Além disso, aumentaram as tensões e o questionamento, por parte de alguns docentes, acerca da centralidade do processo de AA nos resultados: "houve uma maior preocupação com os resultados, sim houve, dado o estabelecimento de metas, o que por vezes também pode ter um reflexo negativo pois o atingir a meta pode ser fictício"(AG2-E3); assim sendo "deveria haver uma grande reflexão, nomeadamente ao nível do sucesso e insucesso, (...) se ele é real ou se é artificial" (AG2-E4). Percebe-se assim a preocupação dos docentes com a "obsessão pelas estatísticas" (Machado, 2010) e que a tendência para o "tecnicismo" remeta para o risco de uma "visão em túnel" (Ehren \& Visscher, 2006) e para uma secundarização das aprendizagens não mensuráveis. Estes aspetos são indicadores de que a AA ao ter o seu foco na medição das performances está ao serviço da direção da escola como instrumento de "gestão" e legitimação permitindo justificar no "jogo" da oferta e da procura, ditado pelo mercado, a credibilidade da escola. Face à análise constata-se que, em todas as escolas, a AA, mais do que contribuir para a melhoria contínua, traduz-se no cumprimento de um "ritual de legitimação" (caso das escolas AG1, AG3 e ES2) ou num "gerenciamento da imagem pública" (Ball, 2001) (caso das escolas AG2 e ES1).

\section{Considerações finais}

Da análise resulta que, embora a autoavaliação apareça, em Portugal, como obrigatória (Lei $\mathrm{n}^{\mathrm{o}}$ 31/2002), sendo a escola "uma organização educativa complexa" (Lima, 1998), a sua autoavaliação pode estar ao serviço lógicas e agendas diversas (Sá, 2009) que não a da melhoria. A natureza política da avaliação e a existência de diferentes interesses em "jogo" vão contribuir para o reforço das tensões nas escolas sobre os modos de desenvolver a autoavaliação, sobretudo quando a avaliação pode ser usada como instrumento de poder, controlo e sancionamento (Afonso, 2010). A acrescentar à dimensão política da avaliação, estão as dificuldades das escolas em serem capazes de desenvolver de forma autónoma processos de autoavaliação assentes na colaboração e na reflexão crítica e criativa entre todos os atores educativos, com vista à melhoria contínua dos processos de ensino e aprendizagem (Alves \& Correia, 2008; Correia, 2011). Num contexto onde os objetivos são, por vezes, inconsistentes e não consensuais e as tecnologias pouco claras e, frequentemente, mal dominadas, de modo a "manter a face" (Estevão, 1998), e a garantir a legitimidade e a credibilização social, as escolas e os seus atores recorrem a respostas estratégicas (Oliver, 1991) ou "soluções organizacionais", de tal modo que o desenvolvimento dos processos de autoavaliação mais do que alimentarem processos de melhoria na prestação de serviço educativo, configuram o cumprimento de um "ritual de legitimação" ou um "gerenciamento da imagem pública” (Ball, 2001).

\section{Referências bibliográficas}

Afonso, A. J. (2010). Políticas educativas e autoavaliação da escola pública portuguesa: apontamentos de uma experiência. Estudos de Avaliação Educacional, 21 (46), 343-362.

Alaíz, V., Góis, E., \& Gonçalves, C. (2003). Autoavaliação de escolas - Pensar e praticar. Porto: Edições ASA.

Alves, M., \& Correia, S. (2008). A autoavaliação de escola. Um estudo exploratório sobre os dispositivos de autoavaliação das escolas públicas em Portugal. Olhar de professor, 11 (2), 355-382. $\mathrm{http}: / /$ redalyc.uaemex.mx/src/inicio/ArtPdfRed.jsp?iC $\mathrm{ve}=68412830008$

Ball, S. J. (2001). Diretrizes políticas globais e relações políticas locais em educação. Currículo Sem Fronteiras, 1 (2), 99-116.

Bardin, L. (2009). Análise de conteúdo (5ª ed.). Lisboa: Edições 70.

Bolívar, A. (2012). Melhorar os processos e os resultados educativos. $O$ que nos ensina a investigação. Vila Nova de Gaia: Fundação Manuel Leão.

Correia, S. (2011). Dispositivos de autoavaliação de escola: entre a lógica do controlo e a lógica da regulação (Tese de Doutoramento, Universidade do Minho,Braga).

http://repositorium.sdum.uminho.pt/bitstream/1822/19 723/1/Serafim\%20Manuel\%20Teixeira\%20Correia.p df

Costa, J. A. (1998). Imagens Organizacionais da Escola ( $2^{\mathrm{a}}$ ed.). Porto: Asa.

Costa, J. A. \& Ventura, A. (2005). Avaliação e desenvolvimento organizacional. Infância e educação - Investigação e práticas, 7, 148-161.

Crozier, M., \& Friedberg, E. (1977). L' acteur et le système: Les contraintes de l'action collective. Paris: Éditions du Seuil.

DiMaggio, P. J. \& Powell, W. W. (1999). Retorno a la jaula de hierro: el isomorfismo institucional y la racionalidad colectiva en los campos organizacionales. In W. W. Powell \& P. J. DiMaggio (Eds.), El Nuevo Institucionalismo en el Análisis Organizacional (pp. 104-125). México: Universidad Autónoma del Estado de México.

Ehren, M.C.M. \& Visscher, A.J. (2006). Towards a theory on the impact of school inspections. British Journal of Educational Studies, 54 (1), 51-72..

Estêvão, C. (1998). Redescobrir a escola privada portuguesa como organização. Braga: Universidade do Minho.

Figari, G. (2008). A avaliação de escolas: questões, tendências e modelos. In M. P. Alves \& E.A. Machado (Eds.), Avaliação com sentido(s): contributos e questionamentos (pp. 41- 72) Santo Tirso: De Facto Editores. 
Hargreaves, A. (1998). Os professores em tempos de mudança. Amadora: Editora McGraw-Hill.

Leite, C., Rodrigues, L. \& Fernandes, P. (2006). A autoavaliação das escolas e a melhoria da qualidade da educação - um olhar reflexivo a partir de uma situação. Revista Estudos de Curriculares, 4 (1), pp. 21-45.

Machado, E. A. (2010). A autoavaliação de escola: que lógica(s) de regulação?. Elo, 17, 23-31

Oliver, C. (1991). Strategic responses to institutional processes. The Academy of Management Review, 16 (1), 145-179.

Palma, J. B. (2001). O papel das diferentes modalidades de avaliação das escolas na regulação das políticas educativas. Revista do Fórum Português de Avaliação Educacional, 1, 35-39.
Sá, V. (2009). A (auto)avaliação das escolas: virtudes e efeitos colaterais. Ensaio, 17 (62), 87-108.

Torres, L. (2013). Liderança singular na escola plural: as culturas da escola perante o processo de avaliação externa. Revista Lusófona de Educação, 23, 51-76. $\mathrm{http}: / /$ revistas.ulusofona.pt/index.php/rleducacao/artic le/viewFile/3354/2465

Yin, R. K. (2005). Estudo de caso- planejamento e métodos ( $3^{\mathrm{a}}$ ed.). Porto Alegre: Artmed Editora. 